National Marine

Fisheries Service

NOAA
Fishery Bulletin

ar established in 1881 \%
Spencer F. Baird

First U.S. Commissione of Fisheries and founder of Fishery Bulletin

\begin{abstract}
The blacktip shark (Carcharhinus limbatus) is the most commonly captured species in the Florida recreational shark fishery. We aimed to quantify the postrelease mortality of blacktip sharks and to determine whether hook type (circle or J) had any impact on survival. We measured capture variables (e.g., fight time, animal condition, etc.), blood gas analytes, and finescale behavior obtained by using acceleration data loggers for blacktip sharks $(n=31)$ caught on rod and reel by recreational fishermen. Mortalities $(n=3 ; 9.7 \%)$ all occurred within $2 \mathrm{~h}$ after release. Surviving sharks were monitored for 7 to 72 $\mathrm{h}$ (mean: $30 \mathrm{~h}$ [standard deviation (SD) 22]) and behaviorally recovered from capture within $11 \mathrm{~h}$ (SD 2.6), although larger individuals recovered faster. Hook type did not affect where a shark was hooked, animal condition, the likelihood of hook removal, or recovery time. We found relatively low levels of mortality for blacktip sharks caught in the recreational fishery that were kept in the water and had not sustained serious injuries.
\end{abstract}

\title{
The physiological stress response, postrelease behavior, and mortality of blacktip sharks (Carcharhinus limbatus) caught on circle and J-hooks in the Florida recreational fishery
}

\author{
Nicholas M. Whitney (contact author) 1,2 \\ Connor F. White ${ }^{1}$ \\ Paul A. Anderson ${ }^{3,4}$ \\ Robert E. Hueter 5 \\ Gregory B. Skomal6 \\ Email address for contact author: nwhitney@neaq.org \\ ${ }^{1}$ Behavioral Ecology and Physiology Program \\ Mote Marine Laboratory \\ 1600 Ken Thompson Parkway \\ Sarasota, Florida 34236 \\ 2 Anderson Cabot Center for Ocean Life \\ New England Aquarium \\ 1 Central Wharf \\ Boston, Massachusetts 02110 \\ 3 The Florida Aquarium Center for Conservation \\ 701 Channelside Drive \\ Tampa, Florida 33602 \\ ${ }^{4}$ Mystic Aquarium \\ Sea Research Foundation, Inc \\ c/o University of Connecticut at Avery Point \\ 1084 Shennecossett Road \\ Groton, CT 06340 USA \\ ${ }^{5}$ Center for Shark Research \\ Mote Marine Laboratory \\ 1600 Ken Thompson Parkway \\ Sarasota, Florida 34236 \\ ${ }^{6}$ Massachusetts Division of Marine Fisheries \\ 1213 Purchase Street \\ New Bedford, Massachusetts 02740
}

Manuscript submitted 19 January 2017. Manuscript accepted 15 August 2017. Fish. Bull. 115:532-543 (2017).

Online publication date: 14 September 2017. doi: 10.7755/FB.115.4.9

The views and opinions expressed or implied in this article are those of the author (or authors) and do not necessarily reflect the position of the National Marine Fisheries Service, NOAA.
The practice of catch-and-release has become more common in commercial and recreational fisheries in recent decades in order to ensure the sustainability of global fisheries (Bartholomew and Bohnsack, 2005). Although the catch-and-release method is advocated and broadly mandated to minimize impacts on fisheries stocks, postrelease mortality may still occur owing to stress, injuries, and an increased susceptibility to natural predation (Bartholomew and Bohnsack, 2005; Cooke and Schramm, 2007; Raby et al., 2014). In efforts to reduce mortality, management practices are enacted to reduce capture stress and physical trauma and thus, ultimately increase the sustainability of fisheries (Davis, 2002; Cooke and Schramm, 2007).
Most work on the impacts of catch-and-release fishing has focused on teleosts, even though global shark populations are declining and some are experiencing up to $90 \%$ reductions because of over-exploitation and bycatch in commercial fisheries (Ferretti et al., 2010). In addition to population declines from commercial fishing pressure, many elasmobranch stocks are experiencing increased recreational fishing pressure owing to the recent increases in the popularity of recreational shark fishing (Skomal, 2007; Danylchuk et al., 2014). Sharks are generally more susceptible to fishing pressure because of their K-selected life history traits (Hoenig and Gruber, 1990). There is somewhat limited information available on how elasmobranchs handle 
capture stress and few studies have directly measured postrelease mortality because electronic tags can be cost prohibitive (Skomal and Bernal, 2010; Whitney et al., 2016). Studies that have assessed postrelease mortality in elasmobranch fisheries have found that postrelease mortality is variable between species and fisheries but can be quite high in certain circumstances ( $>60 \%$, Sepulveda et al., 2015; for a review of elasmobranch postrelease mortality, see Ellis et al., 2017).

Efforts have been made to link perturbations in blood biochemistry to animal stress and mortality resulting from capture (Wells et al., 1986; Skomal, 2006; Hyatt et al., 2012). Exhaustive exercise such as fighting on a line, typically causes a marked decrease in blood $\mathrm{pH}$ (acidemia) resulting from metabolic (increasing $\mathrm{H}^{+}$as indicated by rising blood lactate and decreasing blood bicarbonate) and respiratory (increasing partial pressure of carbon dioxide $\left[\mathrm{pCO}_{2}\right]$ ) acidoses (Wood, 1991; Milligan, 1996; Kieffer, 2000; Skomal, 2007; Skomal and Bernal, 2010; Skomal and Mandelman, 2012). These physiological indicators, if coupled with quantitative data on postrelease behavior or mortality, can provide insights into causative factors of physiological stress and mortality, as well as potential mitigation measures (Skomal, 2007).

One of the most commonly advocated fishing methods to minimize physical trauma (e.g., gut hooking) and reduce postrelease mortality is the use of circle-hooks (Cooke and Suski, 2004). Over the past decade, studies on the relative impact of circle-hooks vs. traditional Jhooks on pelagic teleosts have indicated that the former reduce the likelihood of injury to the fish by lodging in the mouth or jaw as opposed to the esophagus or stomach, thereby increasing postrelease survivorship with little impact on catch per unit of effort (Skomal et al., 2002; Kerstetter and Graves, 2006; Serafy et al., 2009; Serafy et al., 2012). Empirical data on these variables are lacking in recreational shark fisheries, but there is some evidence that sharks are less likely to be foul-hooked with the use of circle-hooks than with J-hooks (French et al., 2015; Sepulveda et al., 2015; Willey et al., 2016).

A main target species in the southeastern U.S. shark fisheries, both recreational and commercial, is the blacktip shark (Carcharhinus limbatus) (NMFS ${ }^{1}$ ). Although management measures beginning in 1993 have enabled blacktip sharks to rebound from a sharp decline $\left(\mathrm{NMFS}^{1}\right)$, current fishing pressure on the blacktip shark may be increasing as an alternative to pressure on the sympatric sandbar shark (C. plumbeus), which is prohibited to be captured in federal waters $\left(\mathrm{NMFS}^{2}\right)$. The NOAA Marine Recreational Information

\footnotetext{
${ }^{1}$ NMFS (National Marine Fisheries Service). 2006. Final consolidated Atlantic highly migratory species fishery management plan, 1600 p. Highly Migratory Species Manage. Div., Off. Sustainable Fish., Natl. Mar. Fish. Serv., Silver Spring, MD. [Available from website.]

2 NMFS (National Marine Fisheries Service). 2008. Final ammendment 2 to the consolidated Atlantic highly migratory species fishery management plan, 705 p. Highly Migra-
}

Program estimates that blacktip sharks are the most commonly captured shark species in the Florida recreational fishery, with $89 \%$ of individuals released alive after capture (National Marine Fisheries Service Marine Recreational Information Program, Recreational Fisheries Statistics, available from website).

The impact of capture on blacktip sharks is unknown, but the blood biochemistry of blacktip sharks caught on longlines and drum lines indicates that the magnitude of the stress response in this species is greater than that measured in other carcharhinid species, such as sandbar sharks (Mandelman and Skomal, 2009; Marshall et al., 2012; Gallagher et al., 2014). Furthermore, the observed at-vessel mortality rate for this species $(88 \%)$ was much higher than that of the sandbar shark (43\%) in one study of the North Atlantic Ocean longline fishery (Morgan and Burgess, 2007) and therefore raises further concerns about the response of blacktip sharks to capture. However, correlations between blood stress indicators and postrelease mortality have yet to be determined for this species.

In this study, we compared the effects of capture and hook type on blacktip sharks caught in the Florida recreational shark fishery. We compared sharks caught on circle and J-hooks to determine whether blood physiology, or visual at-vessel capture metrics, differed between hook types. We then used multidimensional acceleration data loggers (ADLs) to measure postrelease mortality to determine whether hook type or at-vessel metrics could accurately predict postrelease survival in blacktip sharks. ADLs record the frequency and force of swimming movements, as well as the animal's body orientation at subsecond intervals (e.g., Kawabe et al., 2003; Shepard et al., 2008; Whitney et al., 2012). These high-resolution data can be used to identify and quantify specific behaviors according to tailbeat frequency and amplitude, including active swimming, stalling, gliding, rolling, etc. Recently this technology has been shown to provide definitive measures of mortality and postrelease recovery period in coastal sharks (Whitney et al., 2016).

\section{Materials and methods}

Blacktip sharks were handled in this study in accordance with guidelines of the National Research Council (2011). Work was completed under Florida Fish and Wildlife Conservation Commission permit \#SAL-110041-SRP and approved under Mote Marine Laboratory Institutional Animal Care and Use Committee (IACUC) \#13-11-NW2, as well as the Florida Aquarium ACUC.

\section{Field sites and sampling methods}

We selected 2 study sites off the coast of Florida with a known seasonal prevalence of blacktip sharks:

tory Species Manage. Div., Off. Sustainable Fish., Natl. Mar. Fish. Serv., Silver Spring, MD. [Available from website.] 
Charlotte Harbor and surrounding waters in the Gulf of Mexico $\left(26^{\circ} 47^{\prime} 18^{\prime \prime} \mathrm{N}, 82^{\circ} 7^{\prime} 23^{\prime \prime} \mathrm{W}\right)$, and off Cape Canaveral $\left(28^{\circ} 19^{\prime} 8^{\prime \prime} \mathrm{N}, 80^{\circ} 20^{\prime} 6^{\prime \prime} \mathrm{W}\right)$ in the Atlantic Ocean. At both study sites, specific fishing locations and practices were directed by recreational charter captains to ensure methods were consistent with those commonly used in the recreational fishery. Sharks were caught between September 2011 and April 2013 by using rod and reel with 10/0 circle-hooks (circle offset-point octopus hook; Gamakatsu USA, Inc., Tacoma, WA) or 10/0 J-hooks (straight eye $4 \times$ strong offshore octopus hook; Gamakatsu USA, Inc.) baited with locally caught species, such as Spanish mackerel (Scomberomorus maculatus) and Atlantic bonito (Sarda sarda) and identical angling practices were used regardless of hook type. Once sharks were hooked, they were angled until they could be handled alongside the boat, at which point they were roped by the tail and secured to the side of the vessel with the shark facing toward the bow. The sharks remained in the water to ensure that their gills were oxygenated. The time from when the shark initially was hooked until it was secured alongside the vessel was recorded as fight time. Once secured, precaudal length, girth, and hooking location (jaw, mouth, gill, esophagus, gut, body) were recorded; and sharks were visually assessed for abrasions or bleeding. After initial assessments, an ADL was attached to the shark's dorsal fin and a sample of blood was drawn by a caudal venipuncture. Once sampling and tagging were completed, the hooks were removed or the leaders were cut at the captain's discretion. Blacktip sharks are obligate ram ventilators, but are able to endure short periods of restraint when their gills are flushed by ambient water movement alongside the vessel. If sharks were unresponsive after processing, they were revived by moving them forward and backward in the water to ventilate their gills-a standard practice among recreational fishermen and one recommended in fishery guidelines issued by NOAA and others (e.g., $\mathrm{NMFS}^{3}$ ). Sharks were assigned a behavioral release condition score (BRCS) between 1 and 5 upon release (1=good: no revival time, swiftly swimming away; $2=$ fair: no revival time, slowly swimming away; $3=$ poor: short revival time $<30$ s; $4=$ very poor: long revival time $>30 \mathrm{~s}$; and $5=$ dead: unable to revive), which has been shown to correspond with survival for this species on the basis of long-term recapture rates (see Hueter et al., 2006). The time from when the shark was initially secured to the side of the vessel until it swam away was recorded as handling time. Immediately after release, environmental parameters (temperature, dissolved oxygen) were measured by using a YSI Model 85 probe (YSI, Inc., Yellow Springs, $\mathrm{OH}$ ).

\footnotetext{
${ }^{3}$ NMFS (National Marine Fisheries Service). 2013. Recreational shark fishing-healthy catch \& release. [Available from website.]
}

\section{Blood sampling and analysis}

Once animals were restrained and measured, 1 cc of blood was drawn by caudal venipuncture with an 1820 gauge 3.8-cm nonheparinized syringes (Mandelman and Farrington, 2007; Skomal, 2007). To avoid coagulation and not compromise blood gas accuracy after phlebotomy, sampled whole blood was immediately (within $30 \mathrm{~s}$ ) analyzed for $\mathrm{pH}, \mathrm{pCO}_{2}$, and lactate concentration $\left(\mathrm{La}^{-}\right)$in a portable blood gas analyzer (VetScan i-STAT; Abaxis North America, Union City, CA) thermostatted to $37^{\circ} \mathrm{C}$. These values were then corrected to environmental temperature according to Mandelman and Skomal (2009).

\section{Accelerometer deployment and recovery}

To monitor postrelease mortality and behavior, sharks were tagged with ADLs (G6a; Cefas Technology, Ltd., Lowestoft, UK) set to record tri-axial acceleration at 25 $\mathrm{Hz}$, depth at $1 \mathrm{~Hz}$, and temperature at $0.033 \mathrm{~Hz}$. Acceleration data loggers and a VHF transmitter were embedded in a custom-made float $(7 \times 11 \mathrm{~cm}, 125 \mathrm{~g}$ in air, $70 \mathrm{~g}$ positively buoyant in seawater; Fig. 1) and affixed to the left side of the dorsal fin with plastic cable ties and a galvanic timed release (International Fishing Devices, Inc., Northland, New Zealand; Whitmore et al., 2016). After a predesignated period of time (12-72 $\mathrm{h}$ ), the galvanic release dissolved in seawater, releasing the ADL package and allowing it to float to the surface for recovery. Floating tag packages were detected with a hand-held VHF receiver (R4520C; Advanced Telemetry Systems, Isanti, MN), then retrieved by vessel; for more information on tagging and recovery methods see Lear and Whitney (2016) and Whitmore et al. (2016).

\section{ADL data processing and analysis}

Data from the ADLs were analyzed with Igor Pro software, vers. 6.22 (WaveMetrics, Inc., Lake Oswego, OR) and Ethographer (Sakamoto et al., 2009). Data for each individual's ADL were visually inspected for postrelease mortality, indicated by a constant depth and cessation of tailbeats that were evidence of a lack of movement and, for an obligate ram-ventilating shark, ultimately death (Whitney et al., 2016). Erratic tailbeats could continue for several minutes but, for consistency, time of death was considered to be the final time that the shark came to rest on the seafloor. Using the data from the ADLs, we generated 58 metrics of swim performance according to Whitney et al. (2016). The metrics included tailbeat acceleration amplitude (TBAA), tailbeat cycle (TBC), overall dynamic body acceleration (ODBA; Wilson et al., 2006), and ODBA bursts, while from the depth information we derived number of dives, duration of dives, average depth, and average vertical velocity (VV) for each hour (Whitney et al., 2016). Because sharks are negatively buoyant, their swimming dynamics differ depending on their orientation and vertical direction of travel. 


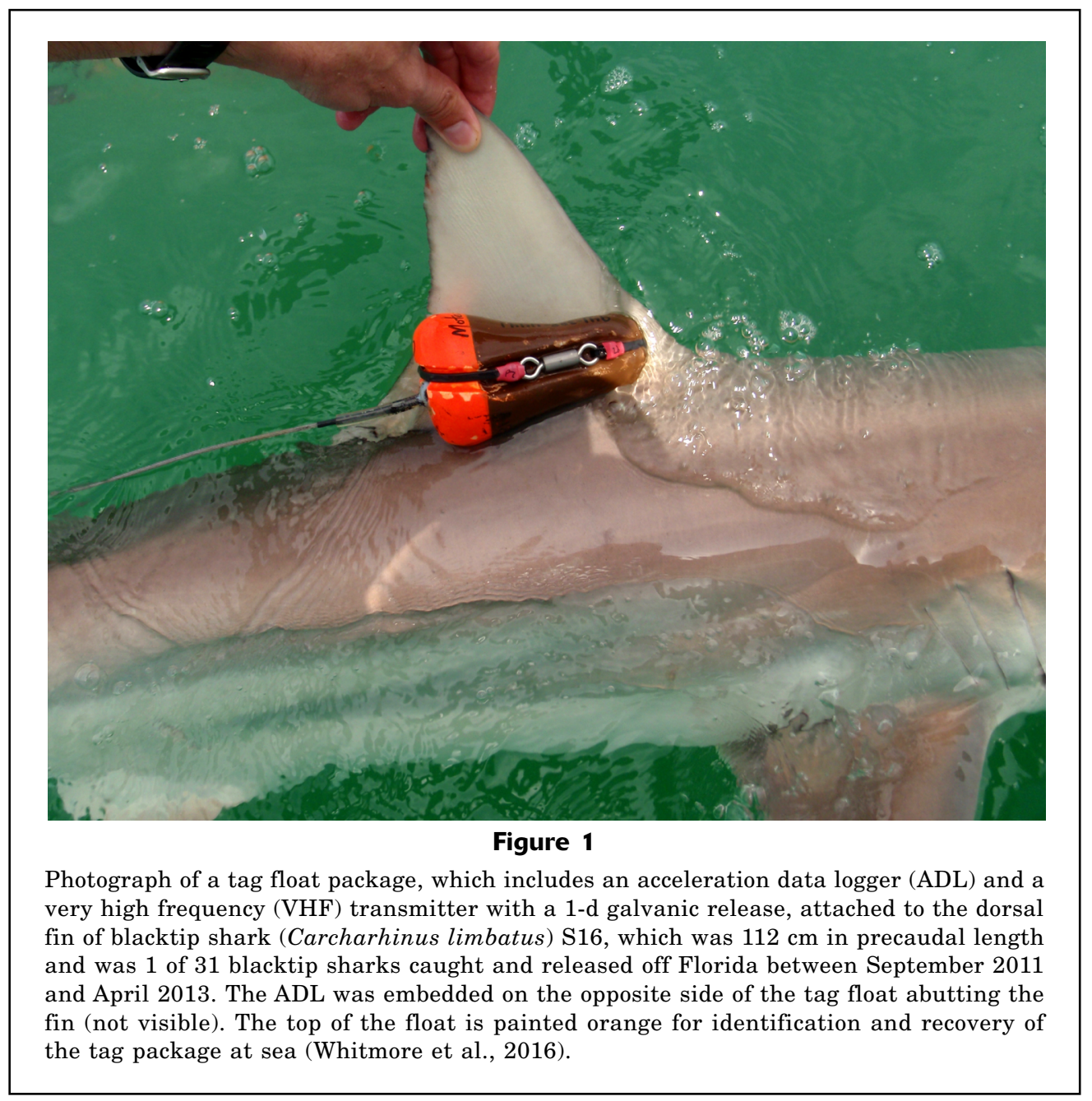

Therefore, we also divided data into descent, ascent, and level phases before statistical analysis (Whitney et al., 2016).

To determine possible recovery period, we took hourly means of each metric, and built asymptotic nonlinear mixed models using the nlme package in the opensource statistical software R, vers. 3.1.0 ( $\mathrm{R}$ Core Team, 2014). Recovery period was defined as the amount of postrelease time it took for the metric value to gain $80 \%$ of the difference between the initial postrelease value and the fully recovered value, defined as the upper asymptote in the logistic equation (Whitney et al., 2016). Metrics shown to display a recovery period were then calculated for each individual (for a more detailed description of these analyses, see Whitney et al., 2016).

\section{Statistical analysis}

All statistical analyses were conducted in $\mathrm{R}$, and all results were reported as means with SDs unless otherwise stated.

At-vessel capture metrics Chi-square tests were performed to test the effect of hook type on the location of hooking (jaw, mouth, gut), the presence of abrasions or bleeding, and the likelihood of the hook being removed by the fisherman (as opposed to the line being cut and the hook left attached to the shark).

Generalized linear models (GLMs) were used to determine which at-vessel capture metrics (temperature, dissolved oxygen, hook type, hooking location, fight time, handling time) affected blood biomarkers $(\mathrm{pH}$, $\mathrm{pCO}_{2}, \mathrm{La}^{-}$), and an ordinal logistic regression (OLR) was used to determine which capture metrics impacted the BRCS. A full complement of all possible models (with the addition and removal of each term) was constructed and compared by using the MuMIn package, vers. 1.15.6, in R. The model with the lowest Akaike's information criterion (AIC) was considered the candidate model and the significance of each term was determined by using the $F$-statistic from an analysis of variance (ANOVA).

Postrelease outcome To investigate the ability of atvessel metrics to determine postrelease outcome, the dimensionality of behavioral recovery periods was reduced by using 2 methods in order to minimize potential type-I error. With the first method, an average 
time to recovery was determined for each individual by averaging the recovery periods across all swimming metrics. GLMs were used to determine which at-vessel metrics (blood biomarkers, environmental and capture metrics) predicted average time to recovery. As with blood biomarker models, a full complement of models was constructed and compared by using AIC, with the significance of the terms in the candidate model determined by an ANOVA.

However, reducing the dimensionality of the recovery period into 1 average negates the possibility that there are multiple ways in which an individual can recover, and these could be affected by different capture parameters. For the second method a principal components analysis (PCA) was conducted on the time to recovery for all swimming metrics. Using the envfit function in the vegan package, vers. 2.3-5, in $R$, we overlaid the at-vessel metrics on the recovery period ordination from the PCA.

\section{Results}

Between September 2011 and April 2013, 31 blacktip sharks were caught and tagged with ADLs (Cape Canaveral, $n=2$; Charlotte Harbor, $n=29$ ), providing a total of $838 \mathrm{~h}$ of acceleration data. The durations of individual ADL records on surviving sharks lasted between 7.1 and $71.7 \mathrm{~h}$ (mean: $30 \mathrm{~h}$ [SD 22]). Precaudal length of the tagged sharks ranged from 92 to $132 \mathrm{~cm}$ (mean: $107.5 \mathrm{~cm}$ [SD 11.2]), and girth ranged from 48 to $81 \mathrm{~cm}$ (mean: $61.2 \mathrm{~cm}$ [SD 7.4]). Fight times lasted between 2 and 16 min (mean: 7 min [SD 3]), and handling times lasted between 6 and 18 min (mean: 9.7 min [SD 2.9]) (Table 1). These times were largely consistent with those practiced by participating recreational captains during their typical charters to take photographs and remove fishing gear (Moore ${ }^{4}$; Rapp ${ }^{5}$ ).

\section{At-vessel capture metrics}

Individuals were captured on both circle $(n=14)$ and Jhooks $(n=17)$, and hooking locations were jaw $(n=22)$, mouth $(n=4)$, and gut $(n=3)$. Hook type did not affect where the shark was hooked $\left(\chi^{2}=0.92, \mathrm{df}=2, P=0.62\right)$, how likely the hook was to be removed by the fisherman $\left(\chi^{2}=1.01, \mathrm{df}=1, P=0.32\right)$, severity of abrasions $\left(\chi^{2}=0.02, \mathrm{df}=1, P=0.89\right)$, observed bleeding $\left(\chi^{2}=0.05\right.$, $\mathrm{df}=1, P=0.82)$, or the BRCS $\left(\chi^{2}=3.34, \mathrm{df}=3, P=0.36\right)$. Additionally, no capture-related variables (hook-type, fight time, $\mathrm{La}^{-}, \mathrm{pCO}_{2}$, and $\mathrm{pH}$ ) significantly affected BRCS (OLR: $P>0.08$ for all predictors).

There was interindividual variability in observed blood biochemical markers (Table 1), yet $\mathrm{pH}$ correlated

\footnotetext{
${ }^{4}$ Moore, R. 2012. Personal commun. Florida Light Tackle Charters. 17044 Greenan Ave., Port Charlotte, FL 33948.

${ }^{5}$ Rapp, D. 2012. Personal commun. Sea Leveler Sport Fishing Charters. 505 Glen Cheek Dr., Cape Canaveral, FL 32920 .
}

with $\mathrm{pCO}_{2}\left(\rho=-0.44, t_{1,29}=-2.66, P=0.01\right)$ and $\mathrm{La}^{-}(\rho=$ $\left.-0.51, t_{1,29}=-3.17, P=0.004\right)$; however, $\mathrm{La}^{-}$was not correlated with $\mathrm{pCO}_{2}\left(\rho=-0.31, t_{1,29}=-1.76, P=0.09\right)$. Hook type, hooking location, and dissolved oxygen were not found to predict biochemical markers and, therefore, were not included in any final predictive models. $\mathrm{La}^{-}$increased (coefficient of multiple determination $\left.\left[R^{2}\right]=0.57\right)$ with increasing fight times $\left(F_{1,28}=12.12\right.$, $P=0.002)$ and handling times $\left(F_{1,28}=25.89, P<0.001\right)$ (Fig. 2, Table 2), whereas increasing handling time was found to significantly lower blood $\mathrm{pH}\left(R^{2}=0.18\right.$, $F_{1,29}=6.44, P=0.02$; Fig. 2, Table 2). Individuals captured at higher temperatures were found to have increased $\mathrm{pCO}_{2}$ levels $\left(F_{1,28}=4.96, P=0.034\right.$; Fig. 2 , Table 2 ). The final model for $\mathrm{pCO}_{2}$ included a negative relationship with fight time, however this was not significant $\left(F_{1,28}=0.63, P=0.43\right)$.

\section{Postrelease outcome}

Mortality All sharks swam away after capture and handling and only 1 individual (S28; BRCS=4; Table 1) needed to be extensively revived (2-3 min until it swam under its own volition) before release. Three of the 31 tagged sharks died after being released as indicated from the acceleration and depth data (Fig. 3 ) representing a postrelease mortality rate of $9.7 \%$. All mortalities occurred within $2 \mathrm{~h}$ of release $(58$, 76 , and $103 \mathrm{~min}$ ), all succumbing individuals were hooked in the jaw, and 2 of the 3 were caught on J-hooks. All 3 confirmed mortalities had a BRCS of "fair." Two of the dead sharks appeared to have been scavenged after the animals sank to the sea floor and had ceased movement for over 30 minutes. The ADLs prematurely released during a series of high intensity movement, an indication of scavenging, and one of the packages displayed bite marks upon recovery (e.g., Lear and Whitney, 2016). Two of the mortalities occurred at high temperatures, and these sharks also had low blood $\mathrm{pH}$ and high La- However, the third mortality occurred for an individual with blood stress values similar to sharks that survived (Fig. 4).

Quantifying sublethal effects Based on the data collected from the ADLs, we determined that 19 of 58 metrics of swimming behavior showed indications of a possible recovery period (for more detail, see Whitney et al., 2016, table 1). Overall, blacktip sharks recovered $10.5 \mathrm{~h}$ (SD 3.8) after release. Larger sharks had a significantly shorter average recovery time than smaller sharks $\left(F_{1,14}=7.83, P=0.014\right.$, Fig. 5$)$; our model also indicated that increasing $\mathrm{pCO}_{2}$ decreases time to recovery, however this term was not significant $\left(F_{1,14}=3.58\right.$, $P=0.079$ ).

The PCA of recovery period showed that the first 2 principal components (PC) accounted for $50.7 \%$ of the variance in the data. $\mathrm{PC} 1$ was correlated with recovery periods determined from average ODBA, TBC, TBAA and average VV, whereas PC2 was correlated with recovery periods determined from maximum ODBA, 


\section{Table 1}

Data records of individual blacktip sharks (Carcharhinus limbatus) caught and released between September 2011 and April 2013 at 2 sites off Florida: Charlotte Harbor and surrounding waters in the Gulf of Mexico and off Cape Canaveral in the Atlantic Ocean. Mortalities are in bold and italics. Sharks were measured in precaudal length. BRCS=behavioral release condition score; $\mathrm{pCO}_{2}=$ partial pressure of carbon dioxide. Recovery period is the averaged behavioral recovery period for that individual over all 19 behavioral metrics and was only calculated for sharks with recording periods over $12 \mathrm{~h}$.

\begin{tabular}{|c|c|c|c|c|c|c|c|c|c|c|c|}
\hline ID & $\begin{array}{l}\text { Length } \\
(\mathrm{cm})\end{array}$ & $\begin{array}{l}\text { Temp } \\
\left({ }^{\circ} \mathrm{C}\right)\end{array}$ & $\begin{array}{l}\text { Hook } \\
\text { type }\end{array}$ & $\begin{array}{l}\text { Fight } \\
\text { time } \\
(\min )\end{array}$ & $\begin{array}{l}\text { Handling } \\
\text { time } \\
\text { (min) }\end{array}$ & BRCS & $\mathrm{pH}$ & $\begin{array}{c}\mathrm{pCO}_{2} \\
(\mathrm{mmHg})\end{array}$ & $\begin{array}{l}\text { Lactate } \\
(\mathrm{mmol} / \mathrm{L})\end{array}$ & $\begin{array}{l}\text { Recording } \\
\text { period } \\
\text { (h) }\end{array}$ & $\begin{array}{c}\text { Recovery } \\
\text { period } \\
\text { (h) }\end{array}$ \\
\hline S01 & 129 & 29.6 & $\boldsymbol{J}$ & 13 & 18 & 2 & 7.1 & 5.06 & 8.57 & 10.4 & - \\
\hline S02 & 97 & 29.9 & $\mathrm{C}$ & 6 & 12 & 1 & 7.18 & 6.01 & 5.67 & 11.4 & - \\
\hline S03 & 102 & 25.2 & $\mathrm{C}$ & 5 & 9 & 1 & 7.29 & 5.85 & 5.62 & 21.4 & 13.4 \\
\hline S04 & 92 & 25.0 & $\mathrm{C}$ & 3 & 14 & 3 & 7.18 & 4.44 & 7.53 & 35.9 & 14.0 \\
\hline S05 & 132 & 25.2 & $\mathrm{C}$ & 11 & 13 & 1 & 7.17 & 4.3 & 7.48 & 57.9 & 8.7 \\
\hline S06 & 98 & 25.3 & $C$ & 5 & 9 & 2 & 7.34 & 5.99 & 3.18 & 8.6 & - \\
\hline S07 & 106 & 24.7 & $\mathrm{~J}$ & 6 & 8 & 1 & 7.18 & 4.61 & 6.76 & 13.8 & 14.2 \\
\hline S08 & 93 & 24.7 & $\mathrm{C}$ & 4 & 10 & 1 & 7.15 & 4.73 & 8.27 & 27.8 & 12.5 \\
\hline $\mathrm{S}_{09}^{\dagger}$ & 95 & 25.3 & $\mathrm{~J}$ & 2 & 10 & 1 & 7.06 & 6.29 & 3.62 & 54.6 & 8.4 \\
\hline $\mathrm{S} 10$ & 101 & 25.4 & $\mathrm{~J}$ & 4 & 6 & 1 & 7.25 & 6.32 & 2.72 & 51.8 & 11.8 \\
\hline $\mathrm{S} 11^{\dagger}$ & 99 & 25.9 & $\mathrm{~J}$ & 4 & 9 & 1 & 7.03 & 10.65 & 5.05 & 7.1 & - \\
\hline $\mathrm{S} 12$ & 92 & 25.9 & $J$ & 4 & 10 & 1 & 7.09 & 10.28 & 4.4 & 7.4 & - \\
\hline S13 & 108 & 25.9 & $\mathrm{~J}$ & 9 & 9 & 1 & 7.31 & 6.09 & 4.81 & 10.7 & - \\
\hline S14 & 128 & 25.1 & $\mathrm{~J}$ & 6 & 8 & 1 & 7.34 & 4.4 & 4.08 & 19.9 & 7.0 \\
\hline S15 & 119 & 24.8 & $\mathrm{~J}$ & 7 & 9 & 1 & 7.27 & 6.98 & 2.97 & 18.8 & 9.2 \\
\hline S16 & 112 & 29.8 & $\mathrm{C}$ & 16 & 9 & 2 & 7.14 & 4.82 & 8.77 & 9.5 & - \\
\hline S17 & 110 & 29.1 & $\mathrm{~J}$ & 10 & 9 & 3 & 7.1 & 10.55 & 5.59 & 54.1 & 10.2 \\
\hline S18 & 120 & 29.3 & $\boldsymbol{J}$ & 13 & 11 & 2 & 7.02 & 6.85 & 10.71 & 2.7 & - \\
\hline S19 & 105 & 29.3 & $\mathrm{~J}$ & 8 & 6 & 1 & 7.18 & 11.64 & 3.07 & 49.4 & 7.2 \\
\hline S20 & 120 & 28.9 & $\mathrm{C}$ & 5 & 6 & 1 & 7.28 & 4.91 & 3.34 & 10.7 & - \\
\hline $\mathrm{S} 21^{\dagger}$ & 105 & 27.0 & $\mathrm{~J}$ & 10 & 10 & 2 & 7.26 & 5.88 & 4.74 & 71.7 & 9.0 \\
\hline S22 & 92 & 27.2 & $\mathrm{C}$ & 5 & 6 & 2 & 7.16 & 8.08 & 4.77 & 68.3 & 12.8 \\
\hline $\mathrm{S} 23$ & 114 & 27.1 & C & 10 & 9 & 1 & 7.22 & 6.03 & 4.53 & 67.7 & 12.2 \\
\hline S24 & 113 & 26.8 & $\mathrm{~J}$ & 10 & 10 & 1 & 7.28 & 6.08 & 4.46 & 11.9 & - \\
\hline S25 & 100 & 26.2 & $J$ & 4 & 6 & 1 & 7.26 & 5.61 & 4.42 & 67.3 & 15.9 \\
\hline S26 & 102 & 27.6 & $\mathrm{C}$ & 6 & 8 & 3 & 7.25 & 6.23 & 4.98 & 11.4 & - \\
\hline S27 & 103 & 27.4 & $\mathrm{C}$ & 5 & 7 & 2 & 7.14 & 11.37 & 4.02 & 9 & - \\
\hline S28 & 108 & 27.3 & $\mathrm{C}$ & 12 & 8 & 4 & 7.21 & 7.2 & 4.52 & 10.4 & - \\
\hline S29 & 108 & 27.3 & $\mathrm{~J}$ & 12 & 10 & 3 & 7.24 & 6.87 & 4.92 & 10.7 & - \\
\hline S30 & 109 & 27.3 & $\mathrm{C}$ & 7 & 7 & 2 & 7.2 & 7.13 & 4.73 & 27.3 & 11.1 \\
\hline S31 & 122 & 27.2 & $\mathrm{~J}$ & 11 & 7 & 1 & 7.36 & 4.82 & 3.83 & 27.2 & 9.4 \\
\hline Mean & 107.5 & 26.9 & & 7.5 & 9.1 & 1.6 & 7.20 & 6.65 & 5.23 & 28.0 & 11.0 \\
\hline SD & 11.2 & 1.7 & & 3.5 & 2.6 & 0.8 & 0.09 & 2.12 & 1.93 & 22.6 & 2.6 \\
\hline
\end{tabular}

Denotes a shark that was gut hooked. The hook was not removed in all 3 cases.

maximum vertical velocity, and the number of ODBA bursts. Increasing handling time and $\mathrm{La}^{-}$corresponded with longer recovery periods along PC1, whereas decreasing temperature, and gut-hooking corresponded with longer recovery times along PC2 (Fig. 6). As found through GLM, increasing animal size correlated with shorter recovery times along PC1 and PC2. However, certain at-vessel capture metrics ( $\mathrm{pH}, \mathrm{pCO} 2, \mathrm{BRCS}$ and hook-type) correlated poorly with the first 2 recovery period PCs.

\section{Discussion}

In this study, we documented 3 postrelease mortalities out of 31 capture and releases (9.7\% mortality) for blacktip sharks caught on rod and reel in the Florida recreational fishery. Our results are consistent with mortality rates for other elasmobranchs caught on rod and reel, such as $10 \%$ for Atlantic sharpnose sharks (Rhizoprionodon terraenovae; Gurshin and Szedlmayer, 2004), 10\% for shortfin makos (Isurus oxyrinchus; 


\section{Table 2}

Parameters and coefficients of determination $\left(r^{2}\right)$ for models of capture metrics that predict blood biomarkers, lactate concentration, acidity $(\mathrm{pH})$, and partial pressure of carbon dioxide $\left(\mathrm{pCO}_{2}\right.$ ), for blacktip sharks (Carcharhinus limbatus) caught and released off Florida during 2011-2013. Values are output of models, representing the equation for the line and the variance accounted for.

\begin{tabular}{lccccc}
\hline & Intercept & $\begin{array}{l}\text { Fight } \\
\text { time }\end{array}$ & $\begin{array}{c}\text { Handling } \\
\text { time }\end{array}$ & Temperature & $r^{2}$ \\
\hline Lactate & -0.6020 & 0.2092 & 0.4660 & - & 0.5758 \\
$\mathrm{pH}$ & 7.3377 & - & -0.0150 & - & 0.1818 \\
$\mathrm{pCO}_{2}$ & -7.3036 & -0.2358 & - & 0.5853 & 0.1664 \\
& & & & &
\end{tabular}

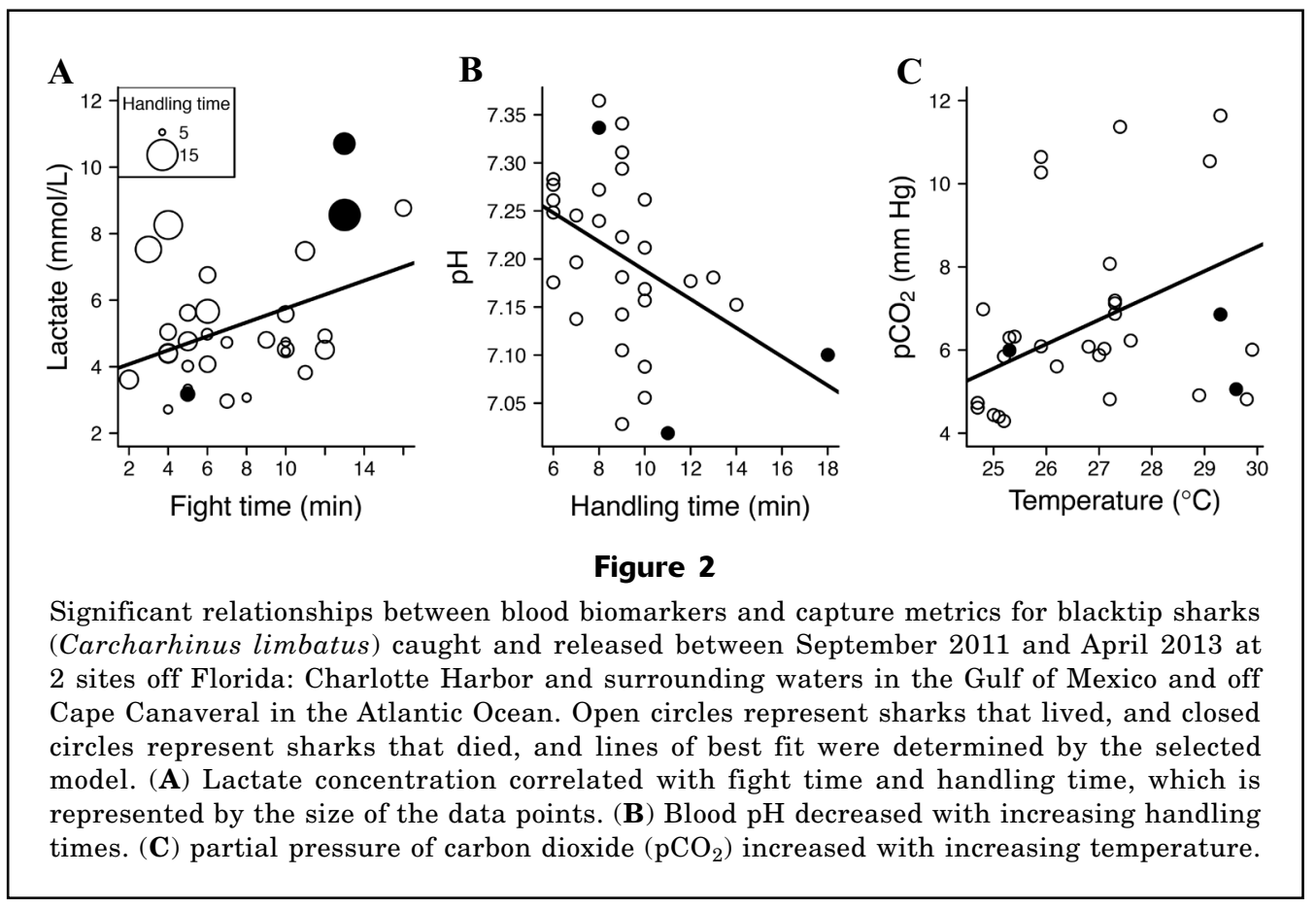

French et al., 2015), and $12.5 \%$ for juvenile lemon sharks (Negaprion brevirostris; Danylchuk et al., 2014). Kneebone et al. (2013) found a lower mortality rate of $1.2 \%$ for juvenile sand tigers (Carcharias taurus), whereas Heberer et al. (2010) found a rate of $26 \%$ for the common thresher shark (Alopias vulpinus). However, the feeding strategy of the common thresher shark is unique and mortality is highly dependent on the type of gear and fishing practice (mouth-hooked $=0 \%$, tail-hooked with trailing gear $=66 \%$; Sepulveda et al., 2015).

Our results were lower than many postrelease mortality rates observed for elasmobranchs captured by commercial fisheries: $24 \%$ for spiny dogfish (Squalus acanthias) in a trawl fishery (Mandelman and Farrington, 2007); $15-31 \%$ for species captured on longlines (Musyl et al., 2011; Marshall et al., 2015; Cam- pana et al., 2016); 43\% for great hammerheads (Sphyrna mokarran) and $26 \%$ for bull sharks (Carcharhinus leucas) captured on drum lines (mortality estimated on the basis of the failure of satellite tags to transmit data; Gallagher et al., 2014); or 48\% for released silky sharks (Carcharhinus falciformis) captured in a purse siene (Poisson et al., 2014). In addition, we observed no at-vessel mortality, which can be as high as $88 \%$ for blacktip sharks caught by demersal longline (Morgan and Burgess, 2007). This finding suggests that the impact of recreational fishing is minimal, with a mortality rate $<10 \%$, and well below the $20 \%$ mortality threshold that is considered unacceptably high for recreational fisheries (Arlinghaus et al., 2007). Although even low rates of postrelease mortality can be detrimental to a stock, depending on its life history and overall fishing pressure, results from a recent assessment suggest that 


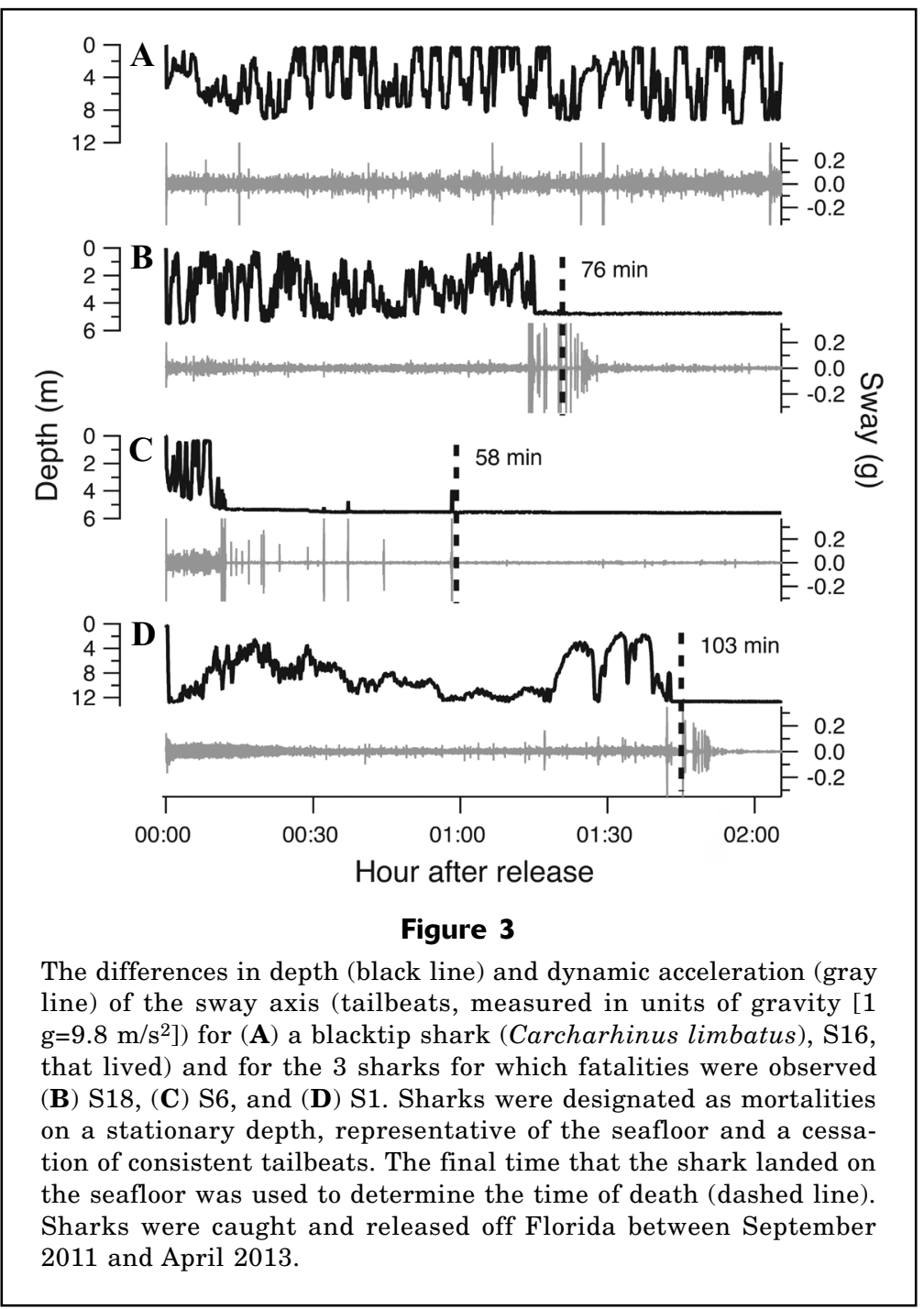

min after release (Gurshin and Szedlmayer, 2004), and juvenile lemon shark mortalities occurred within a 15-min observation period (Danylchuk et al., 2014). Furthermore, for studies that have used longer-term popup satellite tags, mortality was reported to occur shortly after release: $87 \%$ of mortalities happened within 60 min for dusky sharks (Carcharhinus obscurus) and sandbar sharks (Marshall et al., 2015); 100\% of mortalities occurred within $4 \mathrm{~h}$ for common thresher sharks (Heberer et al., 2010); >50\% for blue sharks (Prionace glauca), shortfin makos, and porbeagles (Lamna nasus) died within 6 h of release (Campana et al., 2016); and $>50 \%$ of silky sharks died within 1 day of release (Hutchinson et al., 2015).

Shark mortalities within $10 \mathrm{~d}$ of catch and release are largely attributed to capture-related causes, yet the majority of mortalities that occur within the first $6 \mathrm{~h}$ after release are likely the result of the direct physiological stress of capture (e.g., blood acidosis), or catastrophic hooking injuries (e.g., gill damage or puncture of the peritoneal cavity) (Epperly et al., 2012; Godin et al., 2012; Renshaw et al., 2012; Kneebone et al., 2013). This short time period is within the $11 \mathrm{~h}$ postrelease recovery period measured in our study. Similar duration for behavioral recovery (based on tailbeat frequency) have been observed with juvenile scalloped hammerheads (Sphyrna lewini) after tagging (Lowe, 2001). Furthermore, this behavioral recovery roughly corresponds with the duration of physiological recovery observed in captive sand tigers, whose blood biomarkers returned to baseline within $12 \mathrm{~h}$ (Kneebone et al., 2013).

Some elasmobranchs appear to be able to recover from the physiological stress of capture relatively quickly ( $<1 \mathrm{~d})$. However, differences in physiology, life history, and habitat preference indicate that these results are species or population-specific, and managers should exercise caution before extrapolating such results to other stocks (Mandelman and Skomal, 2009). For instance, Gallagher et al. (2017) recently used accelerometers to show that blacktip sharks fight more intensely than nurse sharks (Ginglymostoma cirratum) and tiger sharks (Galeocerdo cuvier) upon being hooked, and this corresponded to higher $\mathrm{La}^{-}$values.

Studies of blood chemistry of sharks have revealed that capture stress can manifest itself in changes in $\mathrm{La}^{-}$(Hoffmayer and Parsons, 2001; Moyes et al., 2006; Skomal, 2007; Hyatt et al., 2012), hematocrit (Brill et al., 2008; Marshall et al., 2012), $\mathrm{HCO}_{3}$ (Skomal, 2007; Hyatt et al., 2012), K+ (Mandelman and Farrington, 2007; Frick et al., 2010; Marshall et al., 2012), $\mathrm{Ca}^{2+}, \mathrm{Na}^{+}$ (Marshall et al., 2012), and pH (Hoffmayer and Parsons, 2001; Manire et al., 2001; Skomal, 2006; Mandelman
${ }^{6}$ SEDAR (Southeast Data, Assessment, and Review). 2012. SEDAR 29 stock assessment report: HMS Gulf of Mexico blacktip shark, 142 p. SEDAR, North Charleston, South Carolina. [Available from website.] 


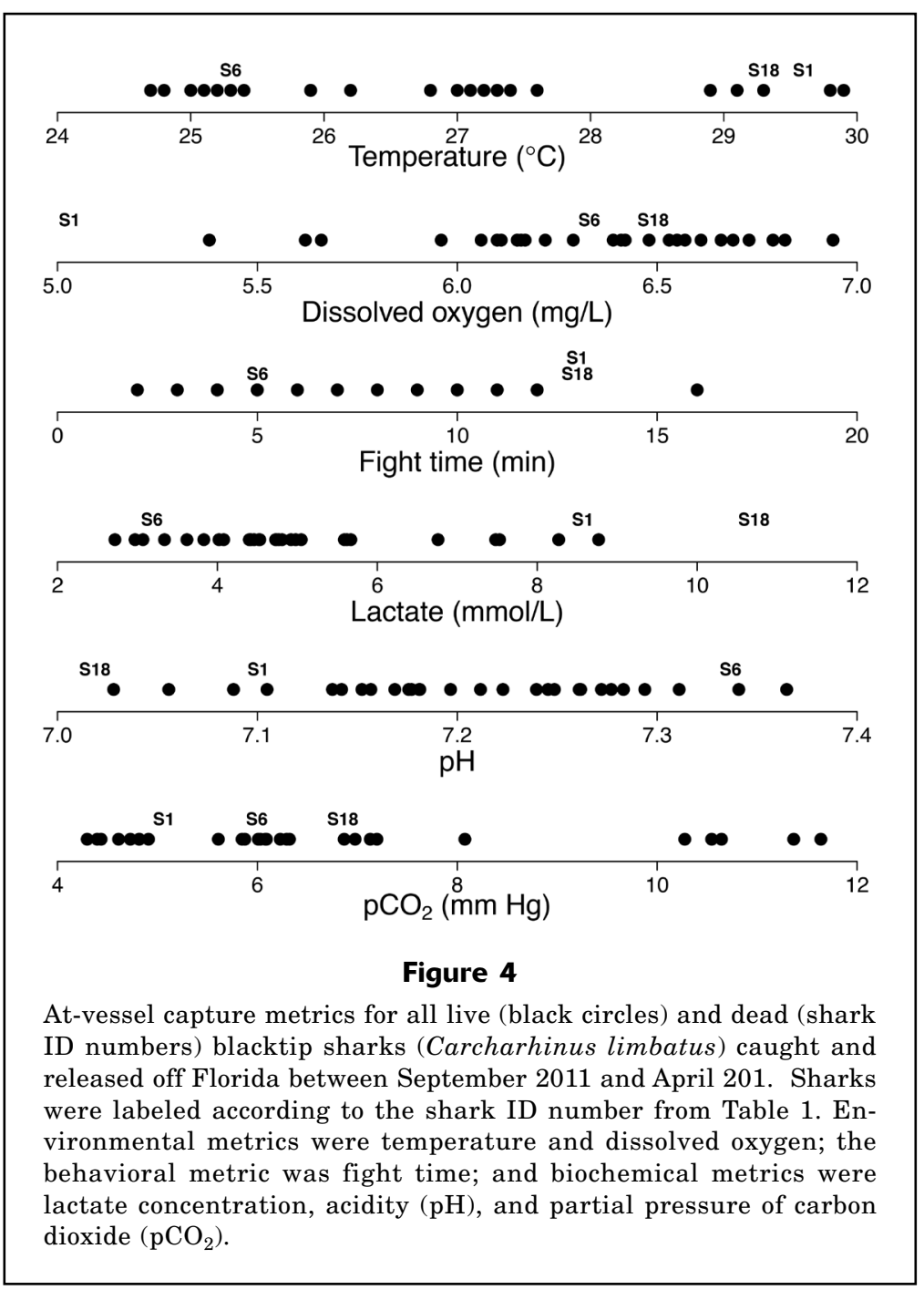

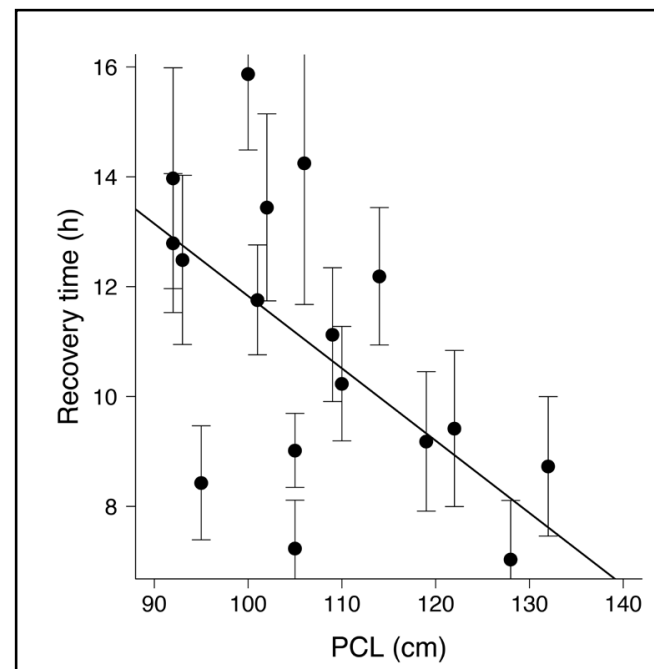

Figure 5

The relationship between precaudal length (PCL) and recovery period, determined with a generalized linear model, for blacktip sharks (Carcharhinus limbatus) caught and released off Florida between September 2011 and April 2013. The relationship is given by the equation $28.1-(0.13 \times \mathrm{PCL})$ $-\left(0.473 \times \mathrm{pCO}_{2}\right)$. The average behavioral recovery period determined from all behavioral metrics was shorter with increasing shark length (coefficient of multiple determination=0.45). Error bars represent standard error of the mean; however, only the means were used in the regression. and Farrington, 2007; Hyatt et al., 2012). Many studies have found significant differences in these physiological indicators between at-vessel moribund and healthy sharks and have used them to predict and extrapolate postrelease mortality. In general, the exhaustive exercise associated with rod and reel capture caused acidbase disruptions in blacktip sharks that increased in magnitude with increasing fight time (decreasing $\mathrm{pH}$; Fig. 2). Concomitant rises in $\mathrm{La}^{-}$and $\mathrm{pCO}_{2}$ indicate that acidemia was of both metabolic and respiratory origin, respectively (Fig. 2). Although these physiological perturbations in acid-base status did not impact survivorship in most of the blacktip sharks sampled, 2 of the 3 mortalities may be linked to these changes in blood chemistry. These 2 sharks were exposed to high water temperatures $\left(>29^{\circ} \mathrm{C}\right.$ ) and long fight times (13 min), and exhibited the highest $\mathrm{La}^{-}$levels, which would indicate blood acidemia driven by metabolic acidosis. This result suggests that higher water temperatures exacerbate the stress response of blacktip sharks and could cause higher levels of postrelease mortality if fight times are ex- tended. However, the third shark that died after release was not exposed to high water temperatures $\left(25.3^{\circ} \mathrm{C}\right)$, had a relatively short fight time $(5 \mathrm{~min})$ and handling time (8 $\mathrm{min})$, and was not experiencing acidemia as indicated by a relatively high $\mathrm{pH}$ and the fourth lowest $\mathrm{La}^{-}$level measured in this study (Fig. 4). This finding suggests that the disruption of acid-base homeostasis may not be the only cause of death after exposure to rod and reel angling.

Previous studies have been able to predict postrelease mortality from blood biochemistry (Moyes et al., 2006; Renshaw et al., 2012); however, because of the small sample size, the low mortality rate, and high variability observed in blood gas values, we were unable to predict postrelease outcome from blood gas analytes. Furthermore, blood biomarkers did not correlate with observed behavioral recovery periods, although larger sharks did display shorter recovery periods. This reduced recovery time could be due to the fact that larger individuals have a lower cost of transport (lower energy requirement for recovery, e.g., Parsons, 1990). 


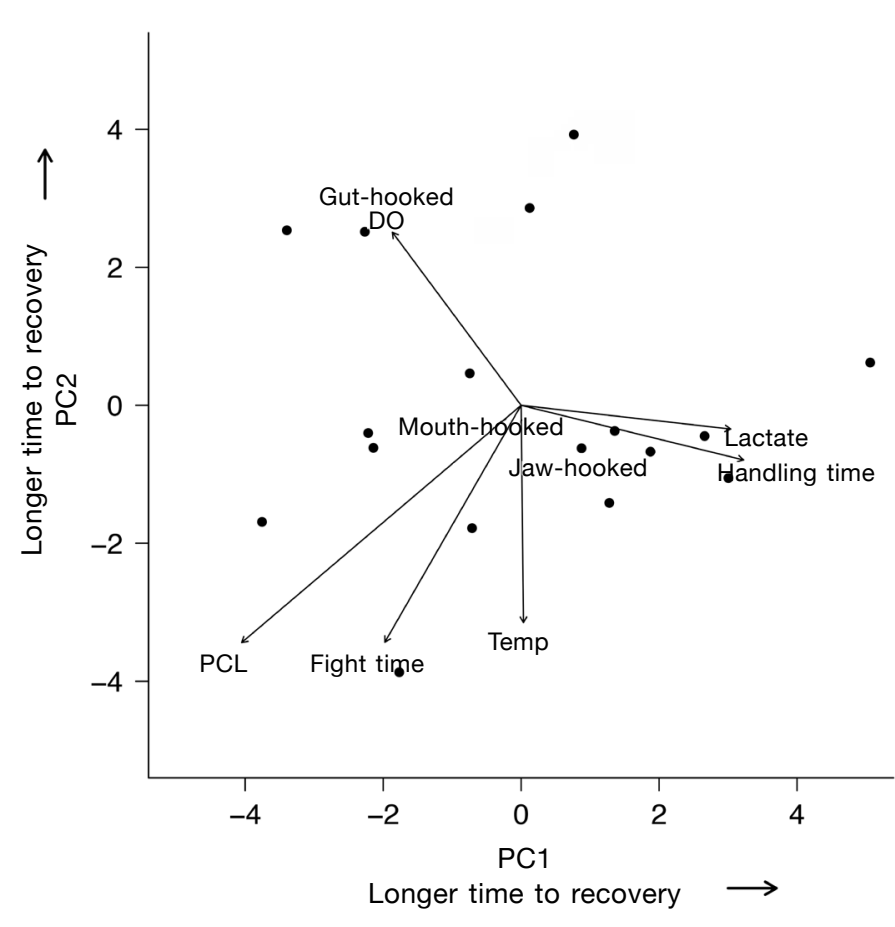

Figure 6

Principal component analysis of the recovery period of blacktip sharks (Carcharhinus limbatus) caught and released off Florida between September 2011 and April 2013. Increasing values along both principal components (PCs) correspond to longer times to recovery. Black circles represent individual sharks. PC1 corresponds to behavioral recovery metrics calculated from averages (average overall dynamic body acceleration [ODBA], tailbeat cycle, tailbeat amplitude, and vertical velocity), and PC2 corresponds to maximum behavioral exertion metrics (maximum ODBA, maximum vertical velocity, and ODBA bursts). Capture metrics, such as dissolved oxygen (DO) of the water at capture location and precaudal length (PCL), are fit onto the recovery period ordination and are displayed as arrows. The direction of the arrow shows the direction and magnitude of its correlation with the behavioral recovery metrics.

In this study, hook type did not affect where a shark was hooked, animal condition, or the likelihood of the fisherman removing the hook. In other recreational fisheries, the use of circle-hooks has been found to increase the likelihood of common thresher sharks and shortfin makos being "mouth hooked" as opposed to "gut or foul hooked" (hooked on the fins or trunk) (French et al., 2015; Sepulveda et al., 2015), as well as increasing the likelihood of jaw-hooking across a range of recreationally caught shark species (Willey et al., 2016). Studies on elasmobranchs captured in commercial fisheries have reported a lower incidence of guthooking with circle-hooks than with J-hooks (Kerstetter and Graves, 2006), and lower at-haulback mortality with circle-hooks (Campana et al., 2009), although the magnitude of this discrepancy is also species-specific.
Overall, we found a relatively low rate of postrelease mortality $(<10 \%)$ and most individuals recovered from capture stress after approximately $11 \mathrm{~h}$. Catch-and-release recreational fisheries may have a low impact on blacktip shark survivorship if animals are kept in the water and have not sustained serious injury.

\section{Acknowledgments}

This study would not have been possible without the expertise and dedication of Captain R. Moore. The authors also thank Captains G. Rapp and D. Rapp for their support, C. Capizzano, H. Marshall, J. Morris, G. Schwieterman, J. Tyminski, and numerous interns and volunteers for their help with fieldwork and other logistics, and K. Heym, S. Coy, V. Wright-Placeres, and K. Casey (Florida Aquarium) for their support in equipment maintenance and accounting. This study was funded by the NOAA Cooperative Research Program, grant no. NA11NMF4540120. This report serves as Sea Research Foundation publication No. 275.

\section{Literature cited}

Arlinghaus, R., S. J. Cooke, J. Lyman, D. Policansky, A. Schwab, C. Suski, S. G. Sutton, and E. B. Thorstad.

2007. Understanding the complexity of catchand-release in recreational fishing: an integrative synthesis of global knowledge from historical, ethical, social, and biological perspectives. Rev. Fish. Sci. 15:75-167. Article

Bartholomew, A., and J. A. Bohnsack.

2005. A review of catch-and-release angling mortality with implications for no-take reserves. Rev. Fish Biol. Fish. 15:129-154. Article

Brill, R., P. Bushnell, S. Schroff, R. Seifert, and M. Galvin.

2008. Effects of anaerobic exercise accompanying catchand-release fishing on blood-oxygen affinity of the sandbar shark (Carcharhinus plumbeus, Nardo). J. Exp. Mar. Biol. Ecol. 354:132-143. Article

Campana, S. E., W. Joyce, M. P. Francis, and M. J. Manning. 2009. Comparability of blue shark mortality estimates for the Atlantic and Pacific longline fisheries. Mar. Ecol. Prog. Ser. 396:161-164. Article

Campana, S. E., W. Joyce, M. Fowler, and M. Showell.

2016. Discards, hooking, and post-release mortality of porbeagle (Lamna nasus), shortfin mako (Isurus oxyrinchus), and blue shark (Prionace glauca) in the Canadian pelagic longline fishery. ICES J. Mar. Sci. 73:520-528. Article

Cooke, S. J., and C. D. Suski.

2004. Are circle hooks an effective tool for conserving marine and freshwater recreational catch-and-release fisheries? Aquat. Conserv. 14:299-326. Article 
Cooke, S. J., and H. L. Schramm.

2007. Catch-and-release science and its application to conservation and management of recreational fisheries. Fish. Manage. Ecol. 14:73-79. Article

Danylchuk, A. J., C. D. Suski, J. W. Mandelman, K. J. Murchie, C. R. Haak, A. M. Brooks, and S. J. Cooke.

2014. Hooking injury, physiological status and short-term mortality of juvenile lemon sharks (Negaprion bevirostris) following catch-and-release recreational angling. Conserv. Physiol. 2:cot036. Article

Davis, M. W.

2002. Key principles for understanding fish bycatch discard mortality. Can. J. Fish. Aquat. Sci. 59:1834-1843. Article

Ellis, J. R., S. R. McCully Phillips, and F. Poisson.

2017. A review of capture and post-release mortality of elasmobranchs. J. Fish Biol. 90:653-722. Article

Epperly, S. P., J. W. Watson, D. G. Foster, and A. K. Shah.

2012. Anatomical hooking location and condition of animals captured with pelagic longlines: the grand banks experiments 2002-2003. Bull. Mar. Sci. 88:513-527. Article

Ferretti, F., B. Worm, G. L. Britten, M. R. Heithaus, and H. K. Lotze.

2010. Patterns and ecosystem consequences of shark declines in the ocean. Ecol. Lett. 13:1055-1071. Article

French, R. P., J. L. Lyle, S. Tracey, S. Currie, and J. M. Semmens.

2015. High survivorship after catch-and-release fishing suggests physiological resilience in the endothermic shortfin mako shark (Isurus oxyrinchus). Conserv. Physiol. 3:cov044. Article

Frick, L. H., R. D. Reina, and T. I. Walker.

2010.vStress related physiological changes and post-release survival of Port Jackson sharks (Heterodontus portusjacksoni) and gummy sharks (Mustelus antarcticus) following gill-net and longline capture in captivity. J. Exp. Mar. Biol. Ecol. 385:29-37. Article

Gallagher, A. J., J. E. Serafy, S. J. Cooke, and N. Hammerschlag.

2014. Physiological stress response, reflex impairment, and survival of five sympatric shark species following experimental capture and release. Mar. Ecol. Prog. Ser. 496:207-218. Article

Gallagher, A. J., E. R. Staaterman, S. J. Cooke, and N. Hammerschlag.

2017. Behavioural responses to fisheries capture among sharks caught using experimental fishery gear. Can. J. Fish. Aquat. Sci. 74:1-7. Article

Godin, A. C., J. K. Carlson, and V. Burgener.

2012. The effect of circle hooks on shark catchability and at-vessel mortality rates in longlines fisheries. Bull. Mar. Sci 88:469-483. Article

Gurshin, C. W. D., and S. T. Szedlmayer.

2004. Short-term survival and movements of Atlantic sharpnose sharks captured by hook-and-line in the northeast Gulf of Mexico. J. Fish Biol. 65:973-986. Article

Heberer, C., S. A. Aalbers, D. Bernal, S. Kohin, B. DiFiore, and C. A. Sepulveda.

2010. Insights into catch-and-release survivorship and stress-induced blood biochemistry of common thresher sharks (Alopias vulpinus) captured in the southern California recreational fishery. Fish. Res. 106:495-500. Article

Hoenig, J. M., and S. H. Gruber.

1990. Life-history patterns in the elasmobranchs: implications for fisheries management. In Elasmobranchs as living resources: advances in the biology, ecology, systematics, and the status of fisheries (H. L. Pratt Jr., S. H. Gruber, and T. Taniuchi, eds.), p. 1-16. NOAA Tech. Rep. NMFS 90.

Hoffmayer, E. R., and G. R. Parsons.

2001. The physiological response to capture and handling stress in the Atlantic sharpnose shark, Rhizoprionodon terraenovae. Fish Physiol. Biochem. 25:277-285. Article

Hueter, R. E., C. A. Manire, J. P. Tyminski, J. M. Hoenig, and D. A. Hepworth.

2006. Assessing mortality of released or discarded fish using a logistic model of relative survival derived from tagging data. Trans. Am. Fish. Soc. 135:500-508. Article

Hutchinson, M. R., D. G. Itano, J. A. Muir, and K. N. Holland.

2015. Post-release survival of juvenile silky sharks captured in a tropical tuna purse seine fishery. Mar. Ecol.: Prog. Ser. 521:143-154. Article

Hyatt, M. W., P. A. Anderson, P. M. O'Donnell, and I. K. Berzins.

2012. Assessment of acid-base derangements among bonnethead (Sphyrna tiburo), bull (Carcharhinus leucas), and lemon (Negaprion brevirostris) sharks from gillnet and longline capture and handling methods. Comp. Biochem. Physiol. A 162:113-120. Article

Kawabe, R., K. Nashimoto, T. Hiraishi, Y. Naito, and K. Sato. 2003. A new device for monitoring the activity of freely swimming flatfish, Japanese flounder Paralichthys olivaceus. Fish. Sci. 69:3-10.

Kerstetter, D. W., and J. E. Graves.

2006. Effects of circle versus J-style hooks on target and non-target species in a pelagic longline fishery. Fish. Res. 80:239-250. Article

Kieffer, J. D.

2000. Limits to exhaustive exercise in fish. Comp. Biochem. Physiol. A 126:161-179. Article

Kneebone, J., J. Chisholm, D. Bernal, and G. Skomal.

2013. The physiological effects of capture stress, recovery, and post-release survivorship of juvenile sand tigers (Carcharias taurus) caught on rod and reel. Fish. Res. 147:103-114. Article

Lear, K. O., and N. M. Whitney.

2016. Bringing data to the surface: recovering data loggers for large sample sizes from marine vertebrates. Anim. Biotelem. 4:12. Article

Lowe, C.

2001. Metabolic rates of juvenile scalloped hammerhead sharks (Sphyrna lewini). Mar. Biol. 139:447-453. Article

Mandelman, J. W., and M. A. Farrington.

2007. The estimated short-term discard mortality of a trawled elasmobranch, the spiny dogfish (Squalus acanthias). Fish. Res 83:238-245. Article

Mandelman, J. W., and G. B. Skomal.

2009. Differential sensitivity to capture stress assessed by blood acid-base status in five carcharhinid sharks. J. Comp. Physiol., B 179:267-277. Article

Manire, C., R. Hueter, E. Hull, and R. Spieler.

2001. Serological changes associated with gill-net capture and restraint in three species of sharks. Trans. Am. Fish. Soc. 130:1038-1048. Article

Marshall, H., L. Field, A. Afiadata, C. Sepulveda, G. Skomal, and D. Bernal.

2012. Hematological indicators of stress in longline-captured sharks. Comp. Biochem. Physiol. A 162:121-129. Article 
Marshall, H., G. Skomal, P. G. Ross, and D. Bernal. 2015. At-vessel and post-release mortality of the dusky (Carcharhinus obscurus) and sandbar (C. plumbeus) sharks after longline capture. Fish. Res. 172:373-384. Article

Milligan, C. L.

1996. Metabolic recovery from exhaustive exercise in rainbow trout. Comp. Biochem. Physiol. A 113:51-60. Article

Morgan, A., and G. H. Burgess.

2007. At-vessel fishing mortality for six species of sharks caught in the Northwest Atlantic and Gulf of Mexico. Gulf Caribb. Res. 19:123-129. Article

Moyes, C. D., N. Fragoso, M. K. Musyl, and R. W. Brill.

2006. Predicting postrelease survival in large pelagic fish. Trans. Am. Fish. Soc. 135:1389-1397. Article

Musyl, M. K., R. W. Brill, D. S. Curran, N. M. Fragoso, L. M. McNaughton, A. Nielsen, B. S. Kikkawa, and C. D. Moyes.

2011. Postrelease survival, vertical and horizontal movements, and thermal habitats of five species of pelagic sharks in the central Pacific Ocean. Fish. Bull. 109:341-368.

National Research Council.

2011. Guide for the care and use of laboratory animals, $8^{\text {th }}$ ed, 220 p. National Academies Press, Washington, DC.

Parsons, G. R.

1990. Metabolism and swimming efficiency of the bonnethead shark Sphyrna tiburo. Mar. Biol. 104:363-367. Article

Poisson, F., J. D. Filmalter, A.-L. Vernet, and L. Dagorn. 2014. Mortality rate of silky sharks (Carcharhinus falciformis) caught in the tropical tuna purse seine fishery in the Indian Ocean. Can. J. Fish. Aquat. Sci. 71:795-798. Article

$\mathrm{R}$ Core Team.

2014. R: a language and environment for statistical computing. R Foundation for Statistical Computing, Vienna, Austria. [Available from website, accessed June 2014.]

Raby, G. D., J. R. Packer, A. J. Danylchuk, and S. J. Cooke.

2014. The understudied and underappreciated role of predation in the mortality of fish released from fishing gears. Fish Fish. 15:489-505. Article

Renshaw, G. M. C., A. K. Kutek, G. D. Grant, and S. Anoopkumar-Dukie.

2012. Forecasting elasmobranch survival following exposure to severe stressors. Comp. Biochem. Physiol. A 162:101-112. Article

Sakamoto, K. Q., K. Sato, M. Ishizuka, Y. Watanuki, A. Takahashi, F. Daunt, and S. Wanless.

2009. Can ethograms be automatically generated using body acceleration data from free-ranging birds? PloS ONE 4(4):e5379. Article

Sepulveda, C. A., C. Heberer, S. A. Aalbers, N. Spear, M. Kinney, D. Bernal, and S. Kohin.

2015. Post-release survivorship studies on common thresher sharks (Alopias vulpinus) captured in the southern California recreational fishery. Fish. Res. 161:102108. Article

Serafy, J. E., D. W. Kerstetter, and P. H. Rice.

2009. Can circle hook use benefit billfishes? Fish Fish. 10: 132-142. Article

Serafy, J. E., S. J. Cooke, G. A. Diaz, J. E. Graves, M. Hall, M. Shivji, and Y. Swimmer.

2012. Circle hooks in commercial, recreational, and arti- sanal fisheries: research status and needs for improved conservation and management. Bull. Mar. Sci. 88:371391. Article

Shepard, E. L. C., R. P. Wilson, L. G. Halsey, F. Quintana, A. Gómez Laich, A. C. Gleiss, N. Liebsch, A. E. Myers, and B. Norman.

2008. Derivation of body motion via appropriate smoothing of acceleration data. Aquat. Biol. 4:235-241. Article

Skomal, G. B.

2006. The physiological effects of capture stress on postrelease survivorship of sharks, tunas, and marlin. Ph.D. diss., 311 p. Boston Univ., Boston, MA.

2007. Evaluating the physiological and physical consequences of capture on post-release survivorship in large pelagic fishes. Fish. Manage. Ecol. 14:81-89. Article

Skomal, G., and D. Bernal.

2010. Physiological responses to stress in sharks. In Sharks and their relatives II: biodiversity, adaptive physiology, and conservation (J. C. Carrier, J. A. Musick, and M. R. Heithaus, eds.), p. 459-490. CRC Press, Boca Raton, FL.

Skomal, G. B., and J. W. Mandelman.

2012. The physiological response to anthropogenic stressors in marine elasmobranch fishes: a review with a focus on the secondary response. Comp. Biochem. Physiol. A 162:146-155. Article

Skomal, G. B., B. C. Chase, and E. D. Prince.

2002. A comparison of circle hook and straight hook performance in recreational fisheries for juvenile Atlantic bluefin tuna. Am. Fish. Soc. Symp. 30:57-65.

Wells, R. M. G., R. H. McIntyre, A. K. Morgan, and P. S. Davie. 1986. Physiological stress responses in big gamefish after capture: observations on plasma chemistry and blood factors. Comp. Biochem. Physiol. A 84:565-571. Article

Whitmore, B. M., C. F. White, A. C. Gleiss, and N. M. Whitney. 2016. A float-release package for recovering data-loggers from wild sharks. J. Exp. Mar. Biol. Ecol 475:49-53. Article

Whitney, N. M., Y. P. Papastamatiou, and A. C. Gleiss.

2012. Integrative multisensor tagging: emerging techniques to link elasmobranch behavior, physiology, and ecology. In Biology of sharks and their relatives, $2^{\text {nd }} \mathrm{ed}$. (J. C. Carrier, J. A. Musick, and M. R. Heithaus, eds.), p. 265-260. CRC Press, Boca Raton, FL.

Whitney, N. M., C. F. White, A. C. Gleiss, G. D. Schwieterman, P. Anderson, R. E. Hueter, and G. B. Skomal.

2016. A novel method for determining post-release mortality, behavior, and recovery period using acceleration data loggers. Fish. Res. 183:210-221. Article

Willey, A. L., L. S. Barker, and M. Sampson.

2016. A comparison of circle hook and J hook performance in the recreational shark fishery off Maryland. Fish. Bull. 114:370-373. Article

Wilson, R. P., C. R. White, F. Quintana, L. G. Halsey, N. Liebsch, G. R. Martin, and P. J. Butler.

2006. Moving towards acceleration for estimates of activity-specific metabolic rate in free-living animals: the case of the cormorant. J. Anim. Ecol. 75:1081-1090. Article

Wood, C. M.

1991. Acid-base and ion balance, metabolism, and their interactions, after exhaustive exercise in fish. J. Exp. Biol. 160:285-308. 